\title{
Effect of Talbinah food consumption on depressive symptoms among elderly individuals in long term care facilities, randomized clinical trial
}

This article was published in the following Dove Press journal:

Clinical Interventions in Aging

6 March 2013

Number of times this article has been viewed

\author{
Manal M Badrasawi \\ Suzana Shahar \\ Zahara Abd Manaf \\ Hasnah Haron \\ Dietetics program, School of Health \\ Care Sciences, Faculty of Health \\ Sciences, Universiti Kebangsaan \\ Malaysia, Kuala Lumpur, Malaysia
}

Correspondence: Suzana Shahar Dietetics Programme,

School of Health Care Sciences, Faculty of Health Sciences, Universiti Kebangsaan Malaysia Jalan Raja Muda Abdul Aziz 50300 Kuala Lumpur, Malaysia Tel +60392897194

Fax +60326938717

Email suzanas@medic.ukm.my

\begin{abstract}
Talbinah is a barley syrup cooked with milk and sweetened by honey. In his famous Hadith on Talbinah, the Prophet Mohammad (SAW) recommended it when sad events happen for its effect on soothing hearts and relieving sadness. This 3-week crossover designed, randomized clinical trial was conducted to determine the effect of Talbinah on mood and depression among institutionalized elderly people in Seremban. A sample of 30 depressed elderly subjects (21 men and 9 women) was selected from the long term care facility. Three different interview-based validated scales (Geriatric Depression Scale, Depression Anxiety Stress Scales, and Profile of Mood States) were used to determine mood, depression, stress, and anxiety at week 0, 3, 4, and 7. The nutritional value of Talbinah was examined using proximate food analysis, minerals content analysis, and differential amino acid analysis. The results indicated that Talbinah is a high carbohydrate food (86.4\%) and has a high tryptophan: branch chain amino acids ratio (1:2). A Wilcoxon nonparametric test showed that there was a statistically significant decrease on depression, stress, and mood disturbances scores among the intervention group $(P<0.05)$ for all parameters. In conclusion, Talbinah has the potential to reduce depression and enhance mood among the subjects. Ingestion of functional foods such as Talbinah may provide a mental health benefit to elderly people.
\end{abstract}

Keywords: Talbinah, food and depression, cross over study, elderly

\section{Background}

Depression among the elderly is a health concern all around the world as it is a major risk factor for Alzheimer's disease. ${ }^{1}$ Depression has been associated with emotional and physical well-being, decreases quality of life, and increases mortality rate. ${ }^{2}$ The prevalence of depression is reported to be higher among the elderly who reside in long term care facilities as compared to community-dwelling elderly. ${ }^{3,4}$

Studies have shown that one of the factors that influence mood and depression is food..$^{5-7}$ Macronutrients and micronutrients have an effect on mood and cognitive function. ${ }^{5,6,8}$ Wurtman hypothesized that higher intake of carbohydrates is associated with less depressed feelings and more energy. ${ }^{9}$ Carbohydrate intake enhances serotonin synthesis by increasing the release of insulin, which facilitates muscle reuptake of amino acids, but not tryptophan, and further increases the ratio between tryptophan and large neutral amino acids (tyrosine, phenylalanine, leucine, isoleucine, and valine) in plasma. This results in an increase of tryptophan availability to the brain which is metabolized to serotonin.

Folic acid and some of the other B vitamins (cobalamin, riboflavin, and pyridoxine) also play major roles in depression and dementia. ${ }^{8}$ An inverse significant relation 
between homocysteine and depression has been reported. ${ }^{10,11}$ Omega 3 fatty acids are also important nutrients that are associated with depression. However, inconsistent findings have been reported for this association. ${ }^{12,13}$

In addition to nutrients, specific food items, such as chocolate, tea, sucrose, and cod liver oil have been studied based on their potential effects to relieve depression. ${ }^{7,14-17}$ However, clinical trials to prove the association are scarce. Thus, the evidence linking specific foods with mental health is limited.

Among Arabs, Talbinah food has been used to relieve depression. It is prepared by cooking ground roasted barley with milk for a few minutes and then sweetened with honey. ${ }^{18}$ Aisha, the Prophet Mohammed's wife, used to recommend Talbinah based on a recommendation by the Prophet Mohammed, peace be upon him. ${ }^{19}$ Aisha used to recommend At-Talbinah for the sick and for those who grieved over a dead person. She used to say "I heard Allah's Apostle saying 'At-Talbinah gives rest to the heart of the patient and makes it active and relieves some of his sorrow and grief." "19 Other than the Hadith and the cultural use, there is little scientific evidence regarding the use of Talbinah in reducing symptoms of depression.

Therefore, the aim of this study was to determine the effect of Talbinah on depression, stress and anxiety, and selected categories of mood (ie, anxiety, tension, depression, dejection, anger, hostility, vigor, fatigue, confusion, and bewilderment) among institutionalized elderly individuals using a clinical trial with a crossover design.

\section{Materials and methods}

The study was conducted at a publicly funded long-term care facility over 7 weeks (3-week intervention, 1-week wash out period, and 3-week intervention), using a crossover randomized clinical trial. The study protocol was approved by the Universiti Kebangsaan Malaysia Ethical Committee. All participants gave their written consent. Data were collected from September to November 2011.

\section{Inclusion criteria}

The inclusion criteria were: participants aged 60 years and over and had been institutionalized for at least 6 months, had depression [Geriatric Depression Scale - Residential (GDS-R) score 3 or above], and good cognitive function (Mini Mental State Examination score above 23).

\section{Exclusion criteria}

The exclusion criteria included those with diabetes, under medical treatment for depression, or who had communication problems.

\section{Sampling procedures}

The sampling procedures (Figure 1) started with screening subjects for depression among residents who were able to communicate and did not have any psychiatric disorders, as informed by the staff and stated in the medical records in the long term care facility. This was done by a counselor working at the facility using the GDS-R.

\section{Sample size calculation}

The sample size was calculated at a $5 \%$ level of significant, $80 \%$ power, to detect a $20 \%$ mean difference, using the mean and standard deviation from a similar study (Rondalli et al, 2010). ${ }^{20}$ The calculated sample size was 31 , with $10 \%$ dropout it becomes 34 .

\section{Intervention steps}

A total of 36 subjects were randomized into two groups (ie, $\mathrm{A}$ and $\mathrm{B}$ ) by random selection of the folded consent form papers, where 18 subjects were placed in each group, as shown in Figure 2. The control group was instructed to consume their habitual food that was provided from the long term care facility; the intervention group was given one serving of Talbinah on a daily basis during morning tea in addition to their habitual diet given by the long term care facility. This study used a ready-made Talbinah available in the markets in Malaysia with the brand name of TALBINAH manufactured by Afaq Company (Kelantan, Malaysia). A total of $25 \mathrm{~g}$ of the ready-to-mix Talbinah was prepared with $100 \mathrm{~mL}$ of warm water and given immediately to the subjects during the intervention. The subjects were assessed for depression, stress, anxiety, mood disturbances, and nutritional status at baseline, 3, 4, and 7 weeks.

Depressive symptoms were assessed using the GDS-R. ${ }^{21}$ Mood disturbances were assessed using the profile of mood states (POMS) 65-item questionnaire. Changes in mood were assessed using the total mood disturbances (TMD) scale in which the 65 items of POMS were included in the scoring. Mood subcategories were scored by dividing the POMS items into six subcategories [anxiety and tension (POMS A-T), depression and dejection (POMS D-D), anger and hostility (POMS A-H), vigor (POMS V), fatigue (POMS F), and confusion and bewilderment (POMS C-B)] in accordance with the POMS manual categorization. ${ }^{22}$ The depression anxiety and stress scale (DASS) 21-item questionnaire was used to determine the changes in depression (DASS-D), stress (DASS-S) and anxiety (DASS-A). ${ }^{23}$

Nutritional status was measured using anthropometric measurements including weight, height, mid upper arm 


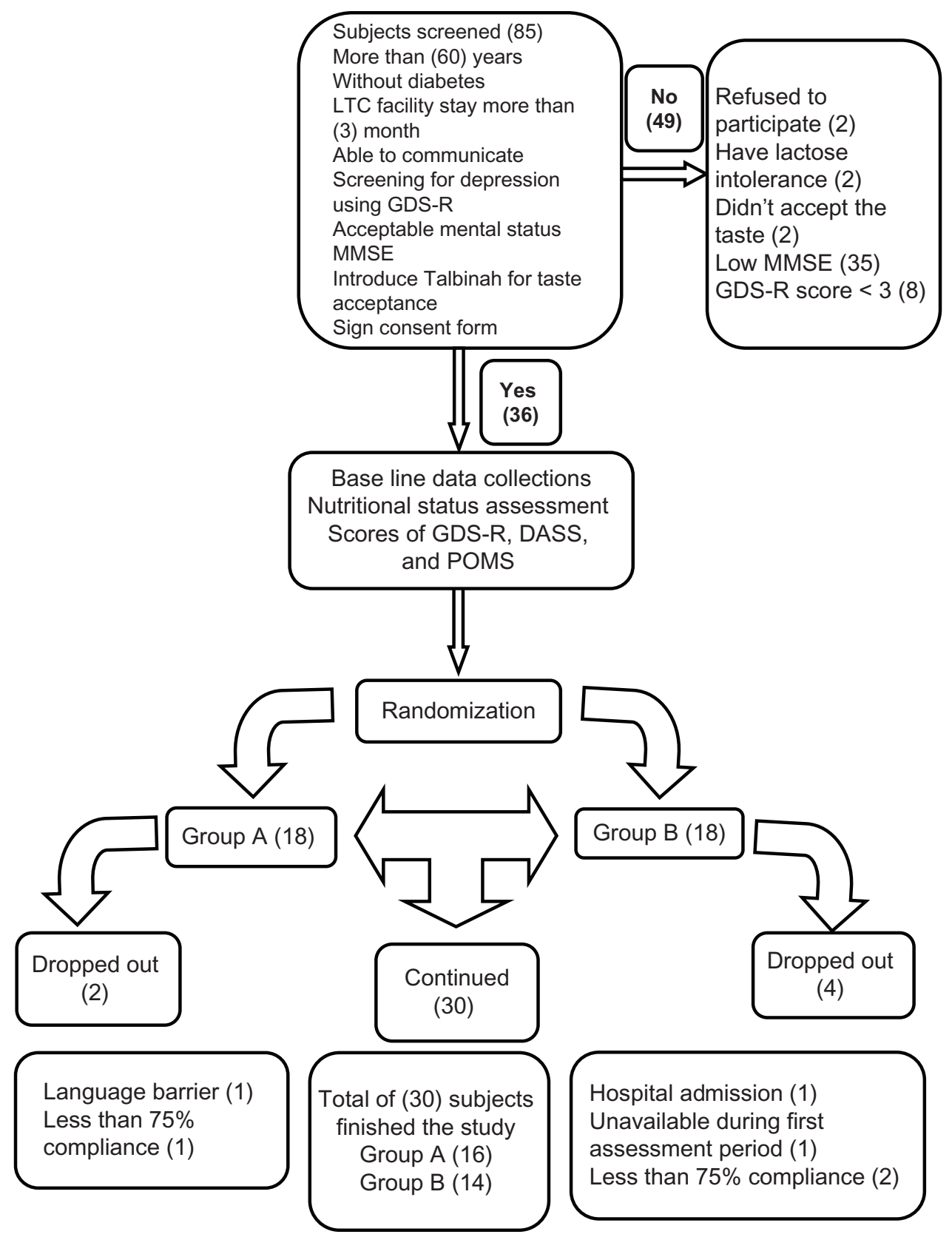

Figure I Sampling procedures.

Abbreviations: GDS-R, Geriatric Depression Scale-Residential; MMSE, Mini Mental Stat Examination; DASS, Depression, Anxiety and Stress Scale; POMS, Profile of Mood Stat LTC, long term care; GDS-R, Geriatric Depression Scale-Residential.

circumference, (MUAC) and calf circumference (CC). Weight was measured using a BC-418 Segmental Body Composition Analyzer (Tanita Corporation, Tokyo, Japan) to the nearest $0.1 \mathrm{~kg}$. Height was measured using a seca 213 stadiometer (seca, Hamburg, Germany) to the nearest $0.1 \mathrm{~cm}$. All measurements were taken twice using a standard method. ${ }^{24}$

Dietary intake was assessed using a 2-day food-weighing record for the main meals and combined with a 24-hour recall for foods consumed in between meals, which was carried out every other day during the intervention. Nutrient analyses were done using Nutritionist Pro software (Axxya Systems, Stafford, TX, USA).

Food analysis of Talbinah was carried out prior to the start of the intervention, in the food analysis laboratory of the Department of Nutrition and Dietetics, Faculty of Health Sciences, University Kebangsaan Malaysia. Four samples from two different batches were used. Proximate food analysis was carried out based on Official methods of analysis of the Association of Official Analytical Chemists. ${ }^{25}$ Analysis of the mineral content was carried out using atomic 


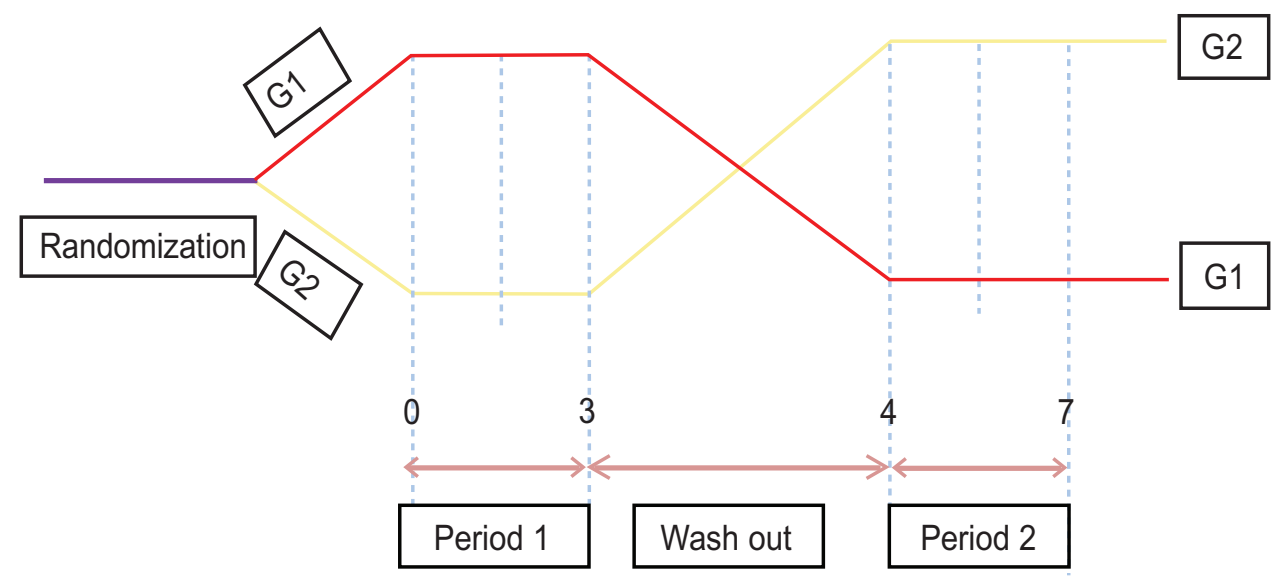

Figure 2 Study design and data collection.

Notes: Week 0: Baseline assessment, Week 3: End of period I, Week 4: End of wash out period, Week 7: End of period 2. GDS-R, DASS, POMS scales were scored at weeks $0,3,4$, and 7 . Nutritional status assessments (weight, height, MUAC, CC, and SGA) were done at weeks 0,3 , 4, and 7 . Two-day food-weighing record was done once during each period.

Abbreviations: GDS-R, Geriatric Depression Scale-Residential; DASS, Depression Anxiety and Stress Scale; POMS, Profile of Mood States; MUAC, mid upper arm circumference; CC, calf circumference; SGA, subjective global assessment.

absorption spectroscopy, and analysis of the differential amino acid content was carried out using high performance liquid chromatography using the Waters AccQ•Tag ${ }^{\mathrm{TM}}$ method.

All statistical analyses were done using the Statistical Package for the Social Sciences version 18 (IBM Corporation, Armonk, NY, USA). Wilcoxon nonparametric tests were conducted to determine the changes in the variables' mean scores in the control and intervention groups before and following intervention.

\section{Results}

\section{Nutritional value of Talbinah}

The energy, macronutrients, ash, moisture, and mineral content of Talbinah were summarized in Table 1. The results showed that Talbinah contains a high amount of total carbohydrates. Based on the differential amino acid analysis,

Table I Nutritional value of Talbinah per serving ${ }^{\mathrm{a}}$

\begin{tabular}{llll}
\hline Item & Content & RNI\% male & RNI\% female \\
\hline Energy & $94 \mathrm{kcal}$ & $4.9 \%$ & $5.2 \%$ \\
Carbohydrate & $21.6 \mathrm{~g}$ & - & - \\
Protein & $1.2 \mathrm{~g}$ & $2 \%$ & $2.3 \%$ \\
Fat & $0.2 \mathrm{~g}$ & - & - \\
Ash & $0.6 \mathrm{~g}$ & - & - \\
Moisture & $1.3 \mathrm{~g}$ & - & - \\
Sodium & $3.1 \mathrm{mg}$ & - & - \\
Magnesium & $14.5 \mathrm{mg}$ & - & - \\
Calcium & $12.7 \mathrm{mg}$ & $1.2 \%$ & $1.2 \%$ \\
Zinc & $5.2 \mathrm{mg}$ & $83.8 \%$ & $\mathrm{I} \% \%$ \\
Iron & $0.34 \mathrm{mg}$ & $2.4 \%$ & $3.1 \%$ \\
\hline
\end{tabular}

Note: aPer serving per $25 \mathrm{~g}$ of dry ready to mix formula. Abbreviation: RNI, Recommended Nutrient Intake. the ratios between the relevant amino acids were calculated. The tryptophan: branch chain amino acids (trp:BCAA) ratio was 18.7:39.3 1:2. The ratio of tryptophan: long chain neutral amino acids (trp:LNAA) was 18.7:388 1:21.

\section{Participant characteristics}

A total of 30 subjects ( 21 men, 9 women) from the originally recruited 36 subjects completed the study. There were 6 subjects who dropped out or were excluded due to low compliance during the intervention.

Most of the subjects were men (70\%), Malays (76.7\%), single $(43.4 \%)$, had a primary education level (6 years of primary schooling) (65.5\%), and nearly half of them (43.3\%) had been residing for more than 3 years at the long term care facility. The mean age of the subjects was 66.8 years.

\section{Nutritional status assessment}

Nutritional status assessment showed that the mean body mass index (BMI) for men was $22.7 \pm 3.7 \mathrm{~kg} / \mathrm{m}^{2}$ in group A and $22.5 \pm 2.3 \mathrm{~kg} / \mathrm{m}^{2}$ in group B. The mean BMI for women was $33.4 \pm 8.5 \mathrm{~kg} / \mathrm{m}^{2}$ in group A (obese categories) and $24.2 \pm 2.9 \mathrm{~kg} / \mathrm{m}^{2}$ in group B (normal weight). There were only 3 subjects (10\%) who were under weight (BMI 16-18.4) ${ }^{26}$, $15(50 \%)$ normal weight (BMI 18.5-24.9) ${ }^{26}, 10$ subjects (33.3\%) overweight (BMI 25-29.9), ${ }^{26}$ and 2 subjects (6.6\%) classified as obese (BMI 30 and above). ${ }^{26}$

MUAC and $\mathrm{CC}$ mean values were over the muscle wasting cutoff points in both genders $(\mathrm{CC}<30.1 \mathrm{~cm}$ for men and $<27.3 \mathrm{~cm}$ for women), (MUAC $<22 \mathrm{~cm}$ for women and $<23 \mathrm{~cm}$ for men). ${ }^{27}$ Muscle assessment showed 
Table 2 Effect of Talbinah on depression, stress, anxiety and mood

\begin{tabular}{|c|c|c|c|c|c|}
\hline \multirow[t]{2}{*}{ Scale name } & \multirow[t]{2}{*}{ Measure of scores } & \multicolumn{2}{|c|}{$\begin{array}{l}\text { Intervention group } \\
(\mathrm{n}=30)\end{array}$} & \multicolumn{2}{|c|}{$\begin{array}{l}\text { Control group } \\
(n=30)\end{array}$} \\
\hline & & Mean \pm SD & $P$ value & Mean \pm SD & $P$ value \\
\hline Geriatric Depression Scale- & GDS-R & & & & \\
\hline \multirow[t]{2}{*}{ Residential } & Before intervention & $6.6 \pm 3.1$ & $0.000^{b}$ & $4.4 \pm 2.5$ & 0.453 \\
\hline & After intervention & $3.7 \pm 2.7$ & & $4.77 \pm 2.6$ & \\
\hline Depression Anxiety Stress & DASS-D & & & & \\
\hline \multirow[t]{2}{*}{ Scale-Depression } & Before intervention & $17.1 \pm 10.5$ & $0.000^{\mathrm{b}}$ & $11.1 \pm 5.9$ & 0.053 \\
\hline & After intervention & $7.9 \pm 7.2$ & & $8.6 \pm 7.4$ & \\
\hline Depression Anxiety Stress & DASS-A & & & & \\
\hline \multirow[t]{2}{*}{ Scale-Anxiety } & Before intervention & $11.2 \pm 7.6$ & 0.100 & $9.2 \pm 6.04$ & 0.462 \\
\hline & After intervention & $8.8 \pm 6.2$ & & $8.7 \pm 6.8$ & \\
\hline Depression Anxiety Stress & DASS-S & & & & \\
\hline \multirow[t]{2}{*}{ Scale-stress } & Before intervention & $13.7 \pm 8.8$ & $0.049^{b}$ & $9.6 \pm 6.6$ & 0.268 \\
\hline & After intervention & $9.9 \pm 7.7$ & & $8.4 \pm 7.6$ & \\
\hline Total mood disturbances using & TMD & & & & \\
\hline \multirow{2}{*}{ profile of mood stat } & Before intervention & $48.5 \pm 36.7$ & $0.000^{\mathrm{b}}$ & $23.4 \pm 18.8$ & 0.713 \\
\hline & After intervention & $25.4 \pm 21.9$ & & $22.2 \pm 17.9$ & \\
\hline Profile of mood stat-anxiety & POMS-A-T & & & & \\
\hline \multirow[t]{2}{*}{ and tension } & Before intervention & $11.7 \pm 6.9$ & $0.002^{b}$ & $7.9 \pm 4.8$ & 0.678 \\
\hline & After intervention & $7.9 \pm 4.8$ & & $7.5 \pm 5.2$ & \\
\hline Profile of mood stat- & POMS D-D & & & & \\
\hline \multirow[t]{2}{*}{ depression and dejection } & Before intervention & $19.5 \pm 10.1$ & $0.00 I^{b}$ & $10.6 \pm 6.4$ & 0.697 \\
\hline & After intervention & $10.0 \pm 7.1$ & & $9.4 \pm 5.9$ & \\
\hline Profile of mood stat-anger & POMS A-H & & & & \\
\hline \multirow[t]{2}{*}{ and hostility } & Before intervention & $11.3 \pm 7.8$ & $0.000^{\mathrm{b}}$ & $6.9 \pm 5.3$ & 0.330 \\
\hline & After intervention & $5.1 \pm 3.8$ & & $8.1 \pm 6.4$ & \\
\hline \multirow[t]{3}{*}{ Profile of mood stat-vigor } & POMS V & & & & \\
\hline & Before intervention & $13.1 \pm 5.8$ & 0.707 & $13.8 \pm 5.1$ & 0.187 \\
\hline & After intervention & $12.4 \pm 4.3$ & & $12.6 \pm 3.2$ & \\
\hline \multirow[t]{3}{*}{ Profile of mood stat-fatigue } & POMS F & & & & \\
\hline & Before intervention & $9.8 \pm 4.7$ & $0.005^{b}$ & $5.3 \pm 3.6$ & 0.321 \\
\hline & After intervention & $6.4 \pm 3.7$ & & $6.4 \pm 4.3$ & \\
\hline Profile of mood stat-confusion & POMS C-B & & & & \\
\hline \multirow[t]{2}{*}{ and bewilderment } & Before intervention & $9.1 \pm 4.2$ & $0.002^{\mathrm{b}}$ & $6.8 \pm 4.3$ & 0.412 \\
\hline & After intervention & $6.2 \pm 2.8$ & & $6.3 \pm 3.4$ & \\
\hline
\end{tabular}

Notes: ${ }^{a}$ Using paired Wilcoxon test; ${ }^{\mathrm{b}} \mathrm{P}<0.05$ significant.

that only $1(3 \%)$ Indian male subject had peripheral muscle wasting based on MUAC, and $3(10 \%)$ subjects (2 Indian males and 1 Malay female) had peripheral muscle wasting using CC. As for the dietary intake, most of the nutrient intakes were below the Malaysian Recommended Nutrient Intake, especially for folate, riboflavin, and calcium.

\section{Changes in depression, stress, anxiety, and mood disturbances mean scores} before and following Talbinah intervention There was a significant decrease in GDS-R, DASS-D, DASS-S, and TMD mean scores following Talbinah intervention compared to the period without. However, there was no significant $(P>0.05)$ decrement in the control group. For example, GDS-R scores decreased in the intervention group, from $6.6 \pm 3.1$ pre-intervention to
$3.7 \pm 2.7$ after intervention. All of the POMS subcategory mean scores were significantly decreased in the intervention group, with the exception of POMS V, $(P<0.05)$ for all parameters. There were no significant $(P>0.05)$ changes in all of the parameters mentioned above in the control group.

\section{Effect of Talbinah on dietary intake}

There were significant changes $(P<0.05)$ found in calories, zinc, and magnesium intake throughout the intervention. The mean for calories increased from $1456 \pm 244 \mathrm{kcal} /$ day pre-intervention to $1590 \pm 242 \mathrm{kcal} /$ day after intervention. Daily zinc mean intake increased from $3.7 \pm 0.7 \mathrm{mg}$ /day to $8.7 \pm 0.9 \mathrm{mg} /$ day. Magnesium daily mean intake increased from $127 \pm 27 \mathrm{mg} /$ day to $138 \pm 29 \mathrm{mg} /$ day, all at $P$ value $<0.05$. 


\section{Discussion}

The results of the intervention showed significant effects of Talbinah on reducing depression and enhancing mood. The nutritional composition of Talbinah, mainly the high carbohydrate content, differential amino acid ratio, and zinc content, may be the reason behind this positive effect as found in the literature review.

\section{Nutritional value of Talbinah and its relation to depression}

Several studies have shown that high carbohydrate content has an effect on mood and depression. ${ }^{6,9,29}$ Lieberman et al explicated that the range of carbohydrate between 11 to $13 \mathrm{~g}$ per $100 \mathrm{kcal}$ was considered as high. ${ }^{28} \mathrm{In}$ this study, the analysis showed that the carbohydrate content in the Talbinah food was high at $22.9 \mathrm{~g}$ per $100 \mathrm{kcal}$. The mineral contents in Talbinah which are associated with reduced depression are zinc ${ }^{29,30}$ and magnesium. ${ }^{31}$ The amino acid composition of food is associated with brain serotonin levels, especially trp:BCAA and trp:LNCAA. ${ }^{9}$ Talbinah had the highest ratio of trp:BCAA of 1:2, as compared to milk $(1: 4)^{32}$ and barley $(1: 11){ }^{33}$ The ratio of trp:LNAA in Talbinah was 1:21, while the ratio in milk was $1: 6^{32}$ and barley had a ratio of $1: 23 .^{33}$ The ratio of trp:BCAA may have increased the tryptophan available to the brain.

\section{Effect of Talbinah on depression}

Talbinah is a high carbohydrate food and the relationship between the amount of consumed carbohydrates with depression and mood was positive. The reason may be due to the effect of carbohydrates on serotonin synthesis.

The association between zinc deficiency and depression has been reported in other studies. ${ }^{29,30}$ Lower zinc serum levels have been associated with highly depressed patients. ${ }^{29}$ A Study by Szewczyk et a $l^{30}$ demonstrated the effectiveness of using zinc as a supplement in antidepressant therapy. Thus, the zinc content in Talbinah of $5 \mathrm{mg}$ per serving may have also contributed in reducing depression. Magnesium may play a role in the rapid treatment of depression if it is given as a supplementary dose of (125-300 mg/day)..$^{31}$ The magnesium content in Talbinah was $14.4 \mathrm{mg}$ per serving. Thus, we could not conclude that the effect of Talbinah on depression was due to the magnesium content.

\section{Effect of Talbinah on mood showed a significant decrease in total mood disturbances}

This study found a positive effect of Talbinah on mood. This is probably due to the high carbohydrate content, sugar content, and sweet taste of Talbinah, as these characteristics have been shown to enhance mood. ${ }^{16,17,34}$ The effectiveness of Talbinah on mood subcategories was measured using the POMS scale; five out of six mood subcategories were enhanced following the Talbinah intervention.

\section{Effect of Talbinah on dietary intake}

The Talbinah intervention increased the calories, magnesium, and zinc intakes of the subjects. The positive effects of Talbinah on mood may be due to these improved intakes as most participants' diets were inadequate in energy, magnesium, and zinc. However, despite the high carbohydrate content in Talbinah, it was not enough to show a significant change in the daily carbohydrate intake.

\section{Limitations}

The assessments of depression and mood changes were completely subjective methods. The usage of objective methods of mood assessment such as visual analog scales could provide more accurate results regarding Talbinah effect on mood enhancement.

Both groups, the control and the intervention, lacked blinding and placebo designs. The disproportionate numbers of gender and races limited generalizing the results. The micronutrient content of some important vitamins was not determined in the food analysis due to unavailability of the required techniques at the study area.

\section{Conclusion}

Overall, Talbinah is a nutritious food that could reduce depression, relieve stress, and enhance mood among the institutionalized elderly. The high carbohydrate composition, zinc content, and high trp:BCAA ratio may be the reasons underlying these effects.

Further studies are required to determine the reason behind Talbinah's positive effect on depression and mood (ie, high carbohydrate content, sweet taste, or zinc content). Other studies are required to determine the effectiveness of Talbinah on the various levels of depression (ie, mild, moderate, and severe), on different subjects (adult, teenagers, etc), and by using more objective methods in the assessment of mood and depression.

\section{Acknowledgment}

We thank AFAQ Company for supplying the Talbinah required for the food analysis and intervention.

\section{Disclosure}

The authors report no conflicts of interest in this work. 


\section{References}

1. Luppa M, Luck T, Weyerer S, König HH, Brähler E, Riedel-Heller SG. Prediction of institutionalization in the elderly. A systematic review. Age Ageing. 2010;39(1):31-38.

2. Blazer DG. Depression and social support in late life: a clear but not obvious relationship. Aging Ment Health. 2005;9(6):497-499.

3. Prakash O, Gupta LN, Singh VB, Nagarajarao G. Applicability of 15-item Geriatric Depression Scale to detect depression in elderly medical outpatients. Asian J Psychiatr. 2009;2(2):63-65.

4. Seitz D, Purandare N, Conn D. Prevalence of psychiatric disorders among older adults in long-term care homes: a systematic review. Int Psychogeriatr. 2010;22(7):1025-1039.

5. Hakkarainen R, Partonen T, Haukka J, Virtamo J, Albanes D, Lönnqvist J. Is low dietary intake of omega-3 fatty acids associated with depression? Am J Psychiatry. 2004;161(3):567-569.

6. Benton D, Donohoe RT. The effects of nutrients on mood. Public Health Nutr. 1999;2(3A):403-409.

7. Murakami K, Sasaki S. Dietary intake and depressive symptoms: a systematic review of observational studies. Mol Nutr Food Res. 2010;54(4):471-488.

8. Horrobin DF. Food, micronutrients, and psychiatry. Int Psychogeriatr. 2002;14(4):331-334

9. Wurtman RJ, Wurtman JJ, Regan MM, McDermott JM, Tsay RH, Breu JJ. Effects of normal meals rich in carbohydrates or proteins on plasma tryptophan and tyrosine ratios. Am J Clin Nutr. 2003;77(1):128-132.

10. Güzelcan Y, van Loon P. Vitamin B12 status in patients of Turkish and Dutch descent with depression: a comparative cross-sectional study. Ann Gen Psychiatry. 2009;8:18.

11. Sachdev PS, Parslow RA, Lux O, et al. Relationship of homocysteine, folic acid and vitamin B12 with depression in a middle-aged community sample. Psychol Med. 2005;35(4):529-538.

12. Suzuki S, Akechi T, Kobayashi M, et al. Daily omega-3 fatty acid intake and depression in Japanese patients with newly diagnosed lung cancer. Br J Cancer. 2004;90(4):787-793.

13. Frasure-Smith N, Lespérance F, Julien P. Major depression is associated with lower omega-3 fatty acid levels in patients with recent acute coronary syndromes. Biol Psychiatry. 2004;55(9):891-896.

14. Raeder MB, Steen VM, Vollset SE, Bjelland I. Associations between cod liver oil use and symptoms of depression: the Hordaland Health Study. J Affect Disord. 2007;101(1-3):245-249.

15. Browne JC, Scott KM, Silvers KM. Fish consumption in pregnancy and omega-3 status after birth are not associated with postnatal depression. J Affect Disord. 2006;90(2-3):131-139.

16. Reid M, Hammersley R. The effects of sucrose and maize oil on subsequent food intake and mood. BrJ Nutr. 1999;82(6): 447-455.

17. Macht M, Dettmer D. Everyday mood and emotions after eating a chocolate bar or an apple. Appetite. 2006;46(3):332-336.
18. Aly SE, Hathout AS, Sahab AF. Application of Hazard Analysis Critical Control Points in Dairy Products: A Case Study of Probiotic Talbina. Nature and Science. 2011;9(7):102-113.

19. Al-Bukhari MI. [Food. Hadith 5417]. In Sahih Al-Bukhari. 1st ed. Damascus: Dar Ibn Kather; 2002:1379. Arabic.

20. Rondanelli M, Giacosa A, Opizzi A, et al. Effect of omega-3 fatty acids supplementation on depressive symptoms and on health-related quality of life in the treatment of elderly women with depression: a double-blind, placebo-controlled, randomized clinical trial. J Am Coll Nutr. 2010;29(1):55-64.

21. Sutcliffe C, Cordingley L, Burns A, et al. A new version of the geriatric depression scale for nursing and residential home populations: the geriatric depression scale (residential) (GDS-12R). Int Psychogeriatr. 2000;12(2):173-181.

22. McNair DM, Heuchert JP, Shilony E. Profile of Mood States: Bibliography 1964-2002. Toronto: Multi-Health Systems; 2003.

23. Gloster AT, Rhoades HM, Novy D, et al. Psychometric properties of the Depression Anxiety and Stress Scale-21 in older primary care patients. $J$ Affect Disord. 2008;110(3):248-259.

24. Lee RD, Nieman DC. Nutritional Assessment. Madison: Brown and Benchmark; 1993.

25. Cunniff P. Official methods of analysis of the Association of Official Analytical Chemists. 16th ed. Association of Official Analytical Chemists 1995. Arlington, VA, USA.

26. BMI classification [webpage on the Internet]. Global Database on Body Mass Index. Geneva: World Health Organization; 2006. Available from: http://apps.who.int/bmi/index.jsp. Accessed December 22, 2012.

27. Suzana S Jr, Siti Saifa H. Validation of Nutritional Screening Tools Against Anthropometric and Functional Assessments Among Elderly People in Selangor. Malays J Nutr. 2007;13(1):29-44.

28. Lieberman HR, Wurtman JJ, Chew B. Changes in mood after carbohydrate consumption among obese individuals. Am J Clin Nutr. 1986;44(6):772-778.

29. Szewczyk B, Kubera M, Nowak G. The role of zinc in neurodegenerative inflammatory pathways in depression. Prog Neuropsychopharmacol Biol Psychiatry. 2011;35(3):693-701.

30. Roozbeh J, Sharifian M, Ghanizadeh A, et al. Association of zinc deficiency and depression in the patients with end-stage renal disease on hemodialysis. J Ren Nutr. 2011;21(2):184-187.

31. Eby GA, Eby KL. Rapid recovery from major depression using magnesium treatment. Med Hypotheses. 2006;67(2):362-370.

32. Payne-Botha S, Bigwood EJ. Amino-acid content of raw and heat-sterilized cow's milk. Br J Nutr. 1959;13:385-389.

33. Lásztity R. Cereal Chemistry. 1st English ed. Budapest: Akadémiai Kiadó; 1990.

34. Liu C, Xie B, Chou CP, et al. Perceived stress, depression and food consumption frequency in the college students of China Seven Cities. Physiol Behav. 2007;92(4):748-754.
Clinical Interventions in Aging

\section{Publish your work in this journal}

Clinical Interventions in Aging is an international, peer-reviewed journal focusing on evidence-based reports on the value or lack thereof of treatments intended to prevent or delay the onset of maladaptive correlates of aging in human beings. This journal is indexed on PubMed Central, MedLine, the American Chemical Society's 'Chemical Abstracts

\section{Dovepress}

Service' (CAS), Scopus and the Elsevier Bibliographic databases. The manuscript management system is completely online and includes a very quick and fair peer-review system, which is all easy to use. Visit http://www.dovepress.com/testimonials.php to read real quotes from published authors. 